\title{
Ovarian Cancer Detection in MRI Images using Feature Space and Classification Method $(\mathrm{ABC}-\mathrm{CNN})$
}

\author{
Uroosa Shafi, Sugandha Sharma
}

\begin{abstract}
The most common disease has an adverse effect on women is ovarian cancer. The female generative organ that is placed in the pelvis is similar to the size of the almond. The production of eggs for the reproduction is the part of the ovaries. Ovarian cancer mainly started from the ovaries, ovaries are the reproductive glands that mainly found in the women. The main aim of this paper is detection of the ovarian cancer and is done in stage wise manner. At every stage the cancer images are trained and cancer is detected using $A B C$ - Convolutional Neural Network. The quality of the MRI cancer images are enhanced and selected in accordance to the performance parameters which are accuracy, error rate and processing time. The images are selected by extracting the features to increase the accuracy rate and reduce the cost and the time of the processing. The MRI cancer images are used for detection, classification and extraction algorithms. The selection of the extracted features of the medical images is done through the optimized $A B C$ algorithm. After the extracting features in medicinal images using kernel PCA method. The selected features removes zero values and then optimized the feature vector.The classification process based on the convolutional neural network for training and testing the cancer images in each stage also detecting the quality of the cancer images. The method is evaluated using performance parameter which is signaling to noise ratio. The dataset is created by collecting the medical images from skims (sher-i-kashmir institute of Medical sciences) and Hospital Kashmir. The number of cancer images used 250. There is two kind of images used. Individual is normal image means without or cancer free images the $2^{\text {nd }}$ one are malignant cancer images. Complete number of images used 250 which have 50 medical images of each dataset (Normal, Stage I, Stage II, Stage II and Stage III). The dataset pictures usually include the MRI scan image of PELVIS. The detection and selection of the images through MRI cancer images is in stage wise approach. The quality of the cancer images is improved with peak signal to noise ratio. The evaluated parameters used to increase the accuracy rate and decrease the time of processing.
\end{abstract}

Index Terms: Ovarian cancer, Extracting features, Convolutional Neural Network, Detection and Classification.

\section{INTRODUCTION}

In the last few decades lot of research has been done in detection of the symptoms of the ovarian cancer. The ovarian cancer is regarded as the silent killer because

Revised Manuscript Received on July 22, 2019. India.

Uroosa shafi, College of Engineering, Chandigarh University, Mohali,

Sugandha sharma, College of Engineering, Chandigarh University, Mohali, India. patients in large amount are diagnosed at the last stage and no symptoms were obvious at an early stage.so the disease must be diagnosed at an early stage and treated on the basis of the symptoms [1].The most common disease has an adverse effect on women is ovarian cancer. The female generative organ that is placed in the pelvis is similar to the size of the almond. The production of eggs for the reproduction is the part of the ovaries. Ovarian cancer mainly started from the ovaries, ovaries are the reproductive glands that mainly found in the women. The ovaries in women produce eggs for the reproduction, eggs passes from the fallopian tube in to the uterus. In uterus, the implantation of the fertilized egg and that produces in to fetus. The female hormones estrogen and progesterone are produced through ovaries [2]. The different types of the tumors may grow in the ovaries, some of them are benign (noncancerous) which may not spread outside the ovary part. The noncancerous tumor may be treated by removing the ovary or by removing the part of the ovary which contains the Tumour. The ovarian tumors that are cancerous may spread to other parts of the body in small portions [3].Ovarian tumor based on the various classification methods for the treatment of the disease. The diagnosis of the complex disease such as tumor has been based on the non-molecular characteristics such as tumor tissue, clinical phase and pathological characteristics. In America and across the world, 27\% of women are dead due to unawareness of this disease. The diagnosis at the correct time leads to life saving of the patients [4]. Ovarian cancer is the ninth most common cancer found in females and its ranks fifth in cause of death among the women. The main cause of the increasing rate of the death among the women is due to undiagnosed ovarian cancer because it may reaches from stage 3 to stage 4. To improve the situation a great effort has been done on the early detection of the ovarian cancer because diagnosis of the disease at an early stage leads to high survival rate of the patient [5][6]. The ovarian cancer is the mainly deadly gynecologic malignancy; the less survival rate is the main cause of the early death of the patients. For an example, biomarker of cancer antigen 125 (CA125) is used for early detection of cancer for ovarian cancer detects $50-60 \%$ of the women's in stage 
1 ovarian cancer. The complex biometric samples of the cancer disease can diagnosed specifically through biomarkers. In recent years of the advanced technology, the mass spectrometry based technologies used to detect the cancer diseases [7]. The medial technology with the genetic data has worked in health care and testing the genetics suspects of the common diseases like as cancer, cardiovascular disease, and diabetes [8].The genetic testing may be inherited to breast and the ovarian cancer. The large scale has led to the genetic disease testing with the conditions might be applied. The data must be provide to the persons on the basis of the culture and social economics groups to communicate the data through genetic testing[9] [10].The testing recipients may view the diverse groups with the critical understanding with the risk of the breasts and ovarian cancer. The risk of the breast cancer has increased to large limits in many of the studies in Caucasian [11]. The other report of the African -American women reported through the testing of BRCAI(i) testing proved the risk of the ovarian cancer [12].The best educational methods that considered testing are provided to the physicians where the screening decisions and(ii) behavior have the impact on the testing approach [13].(iii) The present models for the genetic facilities may be inappropriate that used for the genetic testing for(iv) inheriting the vulnerability to breasts and ovarian cancer [14].

Table I:- Sign, Symptoms and Causes in Ovarian Cancer Disease [15]

\begin{tabular}{|l|l|}
\hline Causes & Sign and Symptoms \\
\hline $\begin{array}{l}\text { The growth of the fluid in the } \\
\text { ovary that forms cysts leads } \\
\text { to cancer disease }\end{array}$ & Pain in pelvic or abdomen. \\
\hline $\begin{array}{l}\text { The petechial germ cell leads } \\
\text { to cancer }\end{array}$ & $\begin{array}{l}\text { Suffer during eating or } \\
\text { feeling full quickly. }\end{array}$ \\
\hline $\begin{array}{l}\text { The heredity may be other } \\
\text { cause of this disease }\end{array}$ & $\begin{array}{l}\text { Swelling of abdomen with } \\
\text { weight loss. }\end{array}$ \\
\hline $\begin{array}{l}\text { Malnutrition is the other } \\
\text { cause of this disease. }\end{array}$ & $\begin{array}{l}\text { Upset stomach, } \\
\text { Constipation. }\end{array}$ \\
\hline $\begin{array}{l}\text { The intake of alcohol or } \\
\text { smoking. }\end{array}$ & $\begin{array}{l}\text { Back pain, Change in } \\
\text { menstrual cycle. }\end{array}$ \\
\hline $\begin{array}{l}\text { Analgesics such as aspirin } \\
\text { and acetaminophen may } \\
\text { cause cancer. }\end{array}$ & $\begin{array}{l}\text { Pain during sexual } \\
\text { intercourse. }\end{array}$ \\
\hline
\end{tabular}

Table 1 described about the causes, sign and symptoms in ovarian cancer disease. How to resolve disease issue/ problems with medical treatment? In Artificial Intelligence works to resolve these problems and easy to detect and stage in any cancer disease.

Current work has proposed a kernel PCA algorithm to extract the genuine features based on the texture feature. In this approach, gives a novel method for exploring and verifying non-linear designs in scientific data. K-PCA approach allows a linear PCA approach to non-linear dimensionality reduction. KPCA expands PCA into parametric and non-linear. It is also fit for non-Gaussian database. K-PCA algorithm is extended from PCA approach to representation of non-linear mappings in a high-dimensional feature space. After that the feature extraction, implemented the $\mathrm{AB}-\mathrm{CNN}$ approach to select the feature and classify the stage and detection of the cancer disease. New approach has implemented to select the extracted features follow by three phases: -(i) Employee Bees (ii) Onlooker Bees and (iii) Scouts.

Applying feature selection steps in this research work, it select the valuable features with Fitness Method and after that implement a CNN approach to classify the cancer and stages. It's come under deep learning process and class of the deep neural network, usually implemented to analyzing the cancer diseases, recognition and assessment etc. It evaluates the performance parameters like as an Accuracy Rate (\%), Processing time (ms) and PSNR is an image quality parameter and error rate (Total sum of error rate). Scope of this research work the ovary cancers are becoming a major cause of death rates due to the gynecologic cancer and around 50 per cent women survived from it. The scope of current research suggests:-

The survival of patients in stage III and IV declined which beneficial to the patients because the diagnosis in these stages is harder.

The cancer is detected at the initial stages.

The fast detection of disease performed through artificial approach. fast speed.

The process performed in a short time period and In section 1 described an overview of the Ovarian Cancer, in section 2 a detailed study about the Literature Review. In section 3 explained about the detailed work about the proposed methodology. Sections 4 have detailed overview about the Results and discussions. The conclusion and Future scope explained in Section 5.

\section{LITERATURE SURVEY}

Durfy, S. J and Bowen, D. J et al.,[16]Inspected the learning, assessments, and indicators of enthusiasm for hereditary testing for bosom disease chance in a demographically different gathering of ladies in western Washington who took an interest in a randomized controlled preliminary (RCT) of bosom malignant growth hazard guiding methods. Four gatherings of ladies were overviewed, all with some family ancestry of bosom malignant growth: (a) 307 white ladies; (b) 36 African-American ladies; (c) 87 lesbian/androgynous ladies; and (d) 113 Ashkenazi Jewish ladies. As a feature of the benchmark poll for the RCT, members were gotten some information about their commonality with hereditary testing for bosom disease hazard, their enthusiasm for such testing what's more, sentiments of it, and activities they foreseen dependent on test results.

Vasavi, G and Jyothi, S et al., 2017[17] predominantly focused on ovarian growths, poly sore ovary disorder, fibroids, and different issues identified with gynaecoid issues.

Ovarian sores should have been legitimately distinguished in patient to take correct choice in 
appropriate time. A fitting discovery is required to take choice on medical procedure or for keep a watch out technique. Treatment choices will be viewed as dependent on tumor width. The tumor distance across is estimated and investigated with one of the strategy utilizing estimating instrument ultrasound. In such manner a multi-dimensional parameter examination is required to apply the best possible treatment on patient. The fake insight can be utilized here to identify precisely the heterogeneous structures and harmful development on the suspected organs. Yang, J. and, Kasberg, W. C et al., [18] exploring the potential job of MT1-MMP cytoplasmic build-up phosphorylation in guideline of metastasis-related practices, ovarian malignancy cells that express low endogenous dimensions of MT1-MMP were designed to express wild-type MT1-MMP, a phosphor-mimetic freak (T567E) or a phosphor-insufficient freak (T567A). Results demonstrate that Modulation impacts conduct of both individual cells and multi-cell totals (MCAs). The obtaining of either wild-type or freak MT1-MMP articulation results in changed attachment of epithelial sheets and the development of progressively conservative MCAs with respect to parental cells. Cells communicating MT1-MMP- T567E phosphor-mimetic freaks display upgraded cell relocation. Besides, MCAs shaped from MT1-MMP- T567E-communicating cells stick ardently to both unblemished ex vivo peritoneal explants and 3- dimensional collagen gels. Association of these MCAs with peritoneal mesothelium upsets mesothelium uprightness, uncovering the sub-mesothelium collagen network on which MT1-MMP-T567E MCAs quickly scatter .Schorge, J. O and Modesitt, S. C. et al., [19] proposed a research on screening and surveillance of ovarian cancer. Hazard decreasing salpingo- oophorectomy is the best technique to avoid ovarian malignant growth in these high-chance ladies. Critical hazard decrease is additionally found in the all- inclusive community who utilize oral contraceptives. Since up to $89 \%$ patients with beginning time illness have side effects preceding determination, expanded familiarity with the restorative network may encourage further workup in patients. Not with standing gigantic exertion, there is no proof that normal screening for ovarian cancer is either the high-hazard or all inclusive communities with serum markers, sonograms, or pelvic examinations decreases mortality. Further assessment is expected to decide if any novel biomarkers, or boards of markers, have clinical utility in early identification.

Table II. Analysis of the various literature survey papers

\begin{tabular}{|c|c|c|c|c|}
\hline $\begin{array}{l}\text { Author/ye } \\
\text { ar }\end{array}$ & $\begin{array}{l}\text { Techniq } \\
\text { ue }\end{array}$ & $\begin{array}{l}\text { Conclusi } \\
\text { on }\end{array}$ & $\begin{array}{l}\text { Problem/ } \\
\text { Parame t }\end{array}$ & \\
\hline $\begin{array}{l}\text { Durfy } \\
\text {, S. J } \\
\text { and Bowe n, } \\
\text { D. } \\
\text { J et } \\
\text { al.,[16 } \\
1999\end{array}$ & $\begin{array}{l}\text { Screening } \\
\text { and } \\
\text { recruitm } \\
\text { ent } \\
\text { method. }\end{array}$ & 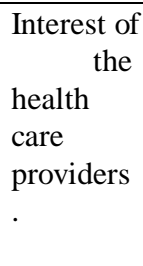 & $\begin{array}{l}\text { Populati } \\
\text { on } \\
\text { testing to } \\
\text { common } \\
\text { diseases. }\end{array}$ & $\begin{array}{l}\text { Mammo } \\
\text { gram } \\
\text { frequenc } \\
\text { y. }\end{array}$ \\
\hline
\end{tabular}

\begin{tabular}{|c|c|c|c|c|}
\hline $\begin{array}{l}\text { Vasav i, G } \\
\text { and Jyoth i, } \\
\text { S et al., } \\
2017[ \\
17] \\
2017\end{array}$ & $\begin{array}{l}\text { Digital } \\
\text { Image } \\
\text { Processi } \\
\text { ng } \\
\text { method. }\end{array}$ & $\begin{array}{l}\text { Diagnosi } \\
\mathrm{s} \text { the } \\
\text { disease at } \\
\text { time or } \\
\text { before the } \\
\text { last } \\
\text { stage. }\end{array}$ & $\begin{array}{l}\text { Problem } \\
\text { in } \\
\text { pregnan } \\
\text { cy and } \\
\text { irregular } \\
\text { menstru } \\
\text { ation. }\end{array}$ & $\begin{array}{l}\text { Classific } \\
\text { ation } \\
\text { rate. }\end{array}$ \\
\hline $\begin{array}{l}\text { Yang, } \\
\text { J. and } \\
\text { ', } \\
\text { Kasb erg, } \\
\text { W. C } \\
\text { et al., } \\
\text { [18] } \\
2017\end{array}$ & $\begin{array}{l}\text { Hanging } \\
\text { drop } \\
\text { method. }\end{array}$ & $\begin{array}{l}\text { Determin } \\
\text { e } \\
\text { behaviou } \\
r \quad \text { of } \\
\text { single cell } \\
\text { and } \\
\text { multicell } \\
\text { ular. }\end{array}$ & $\begin{array}{l}\text { Comple } x \\
\text { structure } \\
\text {. }\end{array}$ & $\begin{array}{l}\text { One way } \\
\text { INNOV } \\
\text { A } \\
\text { recognis } \\
\text { e values } \\
\text { by } \\
\text { compari } \\
\text { ng } \\
\text { groups. }\end{array}$ \\
\hline $\begin{array}{l}\text { Schor ge, J. } \\
\text { O } \\
\text { and Mode } \\
\text { sitt, } \\
\text { S. C. et } \\
\text { al.,[19] } 2010\end{array}$ & $\begin{array}{l}\text { Risk- } \\
\text { reducing } \\
\text { salpingo- } \\
\text { oophorec } \\
\text { tomy } \\
\text { method. }\end{array}$ & $\begin{array}{l}\text { Screening } \\
\text { and } \\
\text { surveilla } \\
\text { nce } \\
\text { the of } \\
\text { ovarian c } \\
\text { ancer. }\end{array}$ & $\begin{array}{l}\text { High risk } \\
\text { of } \\
\text { cancer } \\
\text { disease }\end{array}$ & $\begin{array}{l}\text { Accurac } \\
\text { y, } \\
\text { frequenc } \\
\text { yand } \\
\text { Sonogra } \\
\text { phic } \\
\text { morphol } \\
\text { ogy index }\end{array}$ \\
\hline
\end{tabular}

\section{RESEARCH METHODOLOGY}

In this section, described that the proposed work main objectives are: -

To study and analysis the classification, detection and extraction algorithms in cancer MRI images. To develop an optimization algorithm (ABC) to select the extracted features using three operators (Employee, Onlooker and Scouts) of the medical images. To implement and design the multi-layer architecture (CNN) is to classify the ovarian cancer stage and detection. To evaluate and compare the performance parameters that is Accuracy, Processing Time, Error Rate, PSNR (Peak Signal to Noise Ratio) and Sensitivity. In the initial phase is an image collection of the different databases. A single dataset is stored in the required work. The images from the database are used for the training and testing of the machine learning method using CNN method. The ovarian cancer images are in the .jpg format files. In pre-processing

phase, we upload the image and convert the RGB, gray scale form to reduce the pixel size of the ovarian

cancer image, to identify the interference level in the original image that is MRI ovarian cancer images. Then identify the regions of the cancer image using Sobel Method. After that extract the features in the medical image using K-PCA approach. After, that selects features, then removes the zero values and optimizes the feature vector.

The classification is used CNN to train the cancer images in the each stage dataset and test the cancer detection and enhance the quality of the cancer image (MRI images).

Evaluate the performance parameters, i.e. Accuracy, Error Rate, Sensitivity and Specificity and compared with 
existing approaches i.e. accuracy.

\section{A. Mathematical KPCA algorithm}

Kernel PCA permits for the generation of the PCA to non-linear dimensionality and that can be done using non-linear mapping function. The transformation of samples inputs to high dimensional feature spacing [20].

$$
\varphi=\omega e P^{n} \rightarrow \emptyset\left(\omega_{i}\right) \in \mathrm{F}
$$

Where $\varnothing\left(\omega_{i}\right)$ is the sampling function value of $F$ that is equal to Zero. The mapping function of $\omega_{i}$ is taken as $\emptyset\left(\omega_{i}\right)$ $=\varnothing$ which is covariance matrix of the sampling in the feature space F built as,

$\mathrm{C}=\frac{1}{N} \sum_{J=1}^{N}\left(\emptyset_{J}\right.$-mean value $)\left(\phi_{J}-\right.$ mean $)$

Where the mean have the covariance matrix $C$ that can have the diagonal value with the non-negative Eigenvalues $\tau$ that satisfy the equation,

$$
C_{\mathrm{u}}=\tau_{\mathrm{j}} \mathrm{u} \text {. }
$$

The Eigen vector value with the value $\mathrm{C}$ expressed by,

$\mathrm{u}=\sum_{\mathrm{j}=1}^{\mathrm{N}}\left(\alpha_{\mathrm{j}} \phi_{\mathrm{j}}\right)$.

The coefficients with the $\alpha_{f}$ taken as the kernel matric $\mathrm{k}$ with the size $\mathrm{N} \mathrm{X} \mathrm{N}$ that can describe as the given functional value,

$$
K_{J_{K}}=\emptyset_{J}^{T} \emptyset_{K}=\emptyset_{j} \emptyset_{K}=\mathrm{K}\left(\omega_{j} \omega_{K}\right)
$$

The inner product of the two vectors in $\mathrm{F}$. The projected data set $\emptyset\left(\omega_{i}\right)$ have zero mean, The substitute at the kernel matrix $\mathrm{k}$ having,

$K^{G}=\mathrm{K}-1_{\mathbb{N}} \mathrm{K}-\mathrm{K} 1_{\mathbb{N}}+1_{N}+1_{N} \mathrm{~K} 1_{\mathbb{N}}$

Therefore

$1_{\mathbb{N}}=\frac{1}{N}(\mathrm{NXN})$, the solving value of the Eigen values represented by the equation,

$$
K^{G} \alpha=\mathrm{N} \Gamma \alpha
$$

\section{B. Mathematical AB-CNN algorithm}

$\mathrm{ABC}$ is artificial based colony optimization in which the employed bees connected by the food sources whereas the onlooker bees use the data that collected from the employed bees and the food sources take the place of the scout bees where the onlooker scout bee will find the new food in random locations. The $\mathrm{ABC}$ process can describe in different stages which are initialisation, employing, completion and scouting [21].

\section{Initialise the population}

The generation of the $\mathrm{ABC}$ has uniform distributed population having different solutions where each solution value is $\mathrm{E}$ dimensional Vector. Hence, $\mathrm{E}$ is the number of the variables in optimised factor and each food source generated as,

$$
y_{k}^{j}=y_{\min }^{\tilde{j}}+\operatorname{rand}(0,1)\left(y_{\max }^{\tilde{j}}-y_{\min }^{\tilde{j}}\right), \forall_{k}=
$$

In which $y_{k}^{j}$ and $y_{\min }^{j}$ are the bounding value of $x_{j}$ in $k^{\text {th }}$ direction.

\section{Employing the bee Phase}

In this process, present solution mainly based on the data that is experienced by the fitness function of the new value. The fitness function of the new food source and the bee fitness value with the present food source has high value then the old food sourcing. It can be expressed as,

$$
u_{j k k}=y_{j k}+\phi_{j k}\left(y_{j k}-x_{k i j}\right)
$$

Where $\emptyset_{j, k}\left(y_{j_{j} k}-x_{k l}\right)$ given in step form and then two random function may have the different form of the values with the significant values having the random numbers ranges from $(-1,1)$.

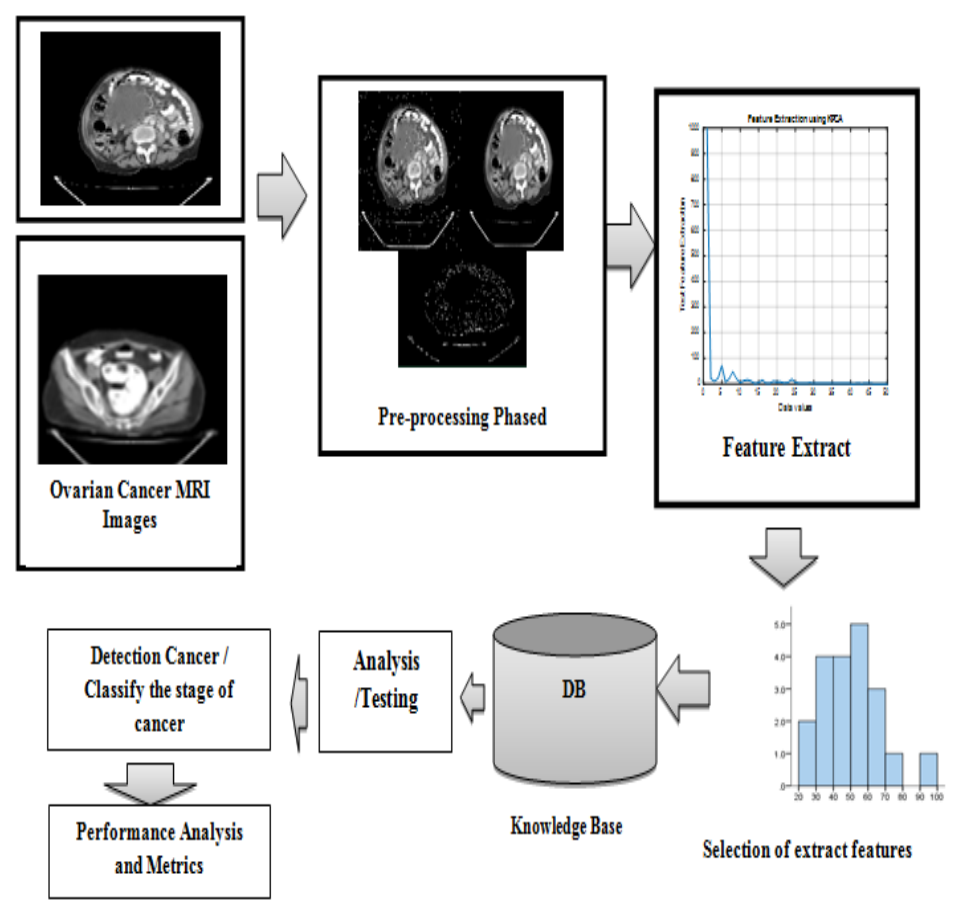

Figure Proposed Flow Chart

\section{Completion Phase}

In this phase the onlooker bees has been started and all the employed bees contribute the fitness value of the food sources and the location data with onlooker bees. The onlooker bees have the data that selects the solution with the probable values that is related to fitness. The probable value is calculated using the fitness function as,

$$
p_{j}=\frac{J \pi_{j}}{\sum_{f=1}^{S S M} f_{\text {it }}}
$$

Where $f$ it ${ }_{j}$ is the fitness value of the $j^{\text {th }}$ solution. The employed bee and the onlooker bees produce the location in the memory and the fitness of the source.

\section{Scouting the bees stage}

The location of the food source is abandoned and then the process of the scout bee may be processed. In this stage, the abandoned food source is assumed and the source of the food becomes scout and food source id random with the search space. In Ant Colony Optimisation the number of the cycles with given parameters have certain limit.

The scout is replaced by food source with values as expressed,

$$
\begin{aligned}
y_{k}^{j}=y_{\min }^{j} & +\operatorname{rand}[0,1]\left(y_{\max }^{j}-y_{\min }^{j}\right) \forall_{k} \\
& =1,2, \ldots \ldots \ldots \ldots \ldots . \mathrm{E}
\end{aligned}
$$

Where $y_{\max }^{j}$ and $y_{\min }^{\tilde{j}}$ are the functional value of $y$. 


\section{RESULT AND DISCUSSION}

In this section, described that the research work dataset is created by collecting the medical images from skims ( sher-i-kashmir institute of medical science ) and Hospital Kashmir. The number of cancer images used 250. There are two kinds of images used. 1st is normal image means without or cancer free images the $2^{\text {nd }}$ one are malignant cancer images. Complete number_of_images used 250 which have 50 medical images of each dataset (Normal, Stage I, Stage II, Stage II and Stage III). The dataset pictures usually include the MRI scan image of PELVIS.

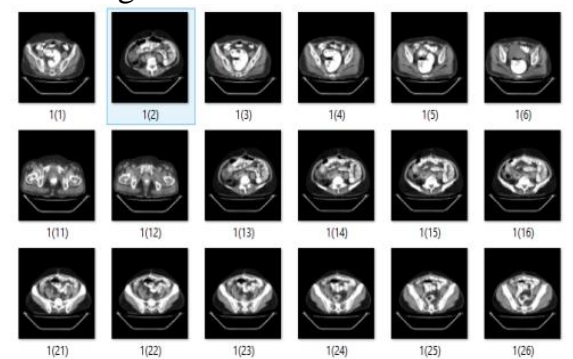

Figure 2. Knowledge Base (Ovarian Cancer Images) It defines that the upload image from the knowledge base folder in cancer and malignant cancer images. Regions perform to detect the cancer region using $\mathrm{ABC}-\mathrm{CNN}$ method and KPCA extraction method applying to fetch the reasonable features or unique properties in the form of texture features.

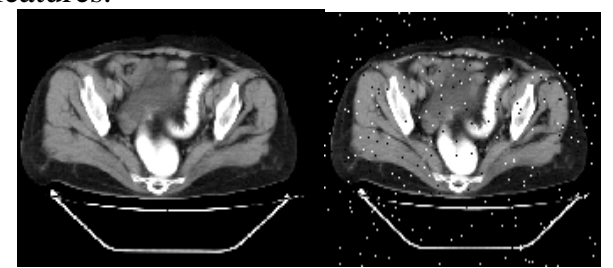

(i)

(ii)

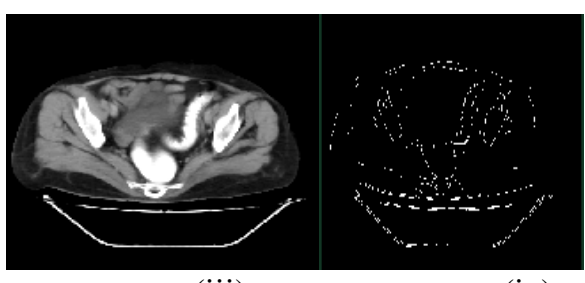

(iii)

(iv)

Figure 3. (i) Test Image (ii) Noise Image (iii) Smooth / Filter Image and (iv) Edge Detector

Above fig 3 (i)define that the upload of the real image from the dataset. To convert the real image into grayscale image from cause of image pixel optimize in 2D form generates. Fig (ii) represents that the noise image means distorted data and blurring of the image 3(iii) Smooth and Filter Image it means to reduce the blurred image from the distorted image and 3(iv) Edge detector means to find the regions in the MRI cancer images. Extract the unique properties with KPCA.

Below fig 4(i) defined that the detected image using segmentation using sobel operator of the MATLAB. The edge operator that uses a single by single edge to detect and the world-wide range of edges or regions in the images.Fig 4(ii) defined that the selected features shown in the bar graph and unique properties to select the reasonable features. Fig 4(iii) applying the distance calculation of the feature comparison then analysis and detect the stage.

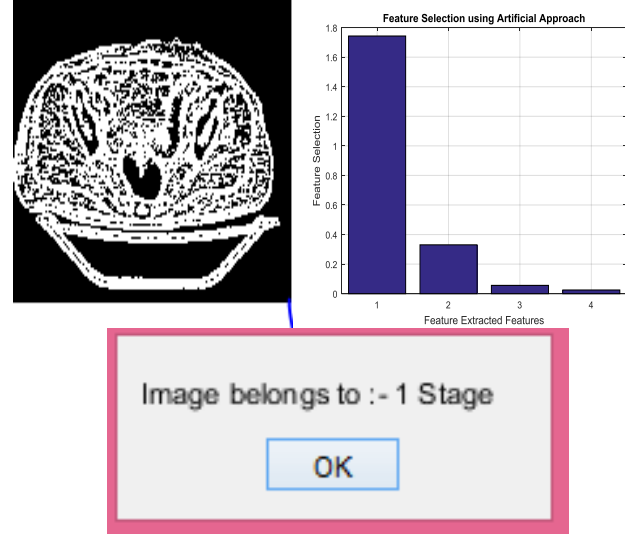

Fig 4(i) Detected Image (ii) Selection of the feature in bar Graph 4(iii) Detection of the cancer stage

Table 2:- Performance Analysis Accuracy, PSNR, ER and Processing Time

\begin{tabular}{|l|l|l|l|l|l|}
\hline Categor & MRI & Accurac & PSNR & ER & Time \\
Images & Y Rate & & & \\
\hline Stage & 98 & 35 & 0.02 & 0.25 \\
\hline Stage 1 & Stage 2 & 98.1 & 35.4 & 0.03 & 0.253 \\
\hline Stage 3 & Stage 4 & 98.3 & 36 & 0.05 & 0.26 \\
\hline & & & 36.7 & 0.08 & 0.28 \\
\hline
\end{tabular}

Above Table 2 described about the performance analysis with parameters in Normal Ovarian Images, Stage 1, Stage 2, Stage 3 and Stage 4 Ovarian cancer MRI Images. The performance measure the Accuracy rate (\%), PSNR Rate (\%), Error Rate, Processing Time.

Below Table 3 define that the sensitivity and specificity rate in proposed work. The analysis was evaluated

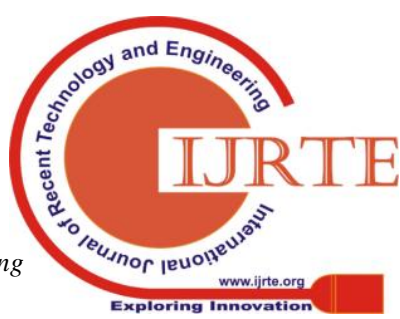


performance metrics in various ovarian cancer stages.

Table 3. Performance analysis (Specificity and sensitivity)

\begin{tabular}{|l|l|l|l|}
\hline Category & $\begin{array}{l}\text { MRI } \\
\text { Images }\end{array}$ & Sensitivity & Specificity \\
Normal & Stage & 0.9 & 0.91 \\
\hline Stage 1 & & 0.92 & 0.93 \\
\hline Stage 2 & Stage 3 & 0.95 & 0.96 \\
\hline
\end{tabular}

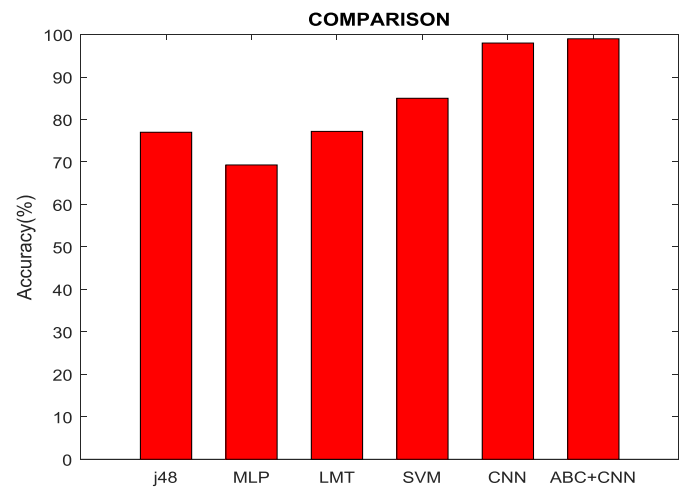

Figure 5. Comparison between proposed and existing workAccuracy Rate (\%)

Table 4: - Comparison Analysis with various Classification Methods

\begin{tabular}{|c|c|}
\hline Methods & Accuracy Rate (\%) \\
\hline J48 classification & 77 \\
\hline MLP & 69.3 \\
\hline LMT & 77.2 \\
\hline SVM & 85 \\
\hline CNN & 98 \\
\hline Proposed & 98.9 \\
\hline
\end{tabular}

Above fig 5 and Table 4 defined that the comparison between proposed and existing works in Accuracy Rate (\%). It can be see that the j48, MLP, LMT, SVM , CNN and ABC+CNN algorithms offer better accuracy rate $(\%)$ than $\mathrm{ABC}+\mathrm{CNN}$ algorithm. After that collecting the consequences, the highest classification was around accuracy rate $98.9 \%$ and PSNR $35.2 \%$ the database was closely studied.

\section{CONCLUSION AND FUTURE SCOPE}

In this conclusion, detection of the ovarian cancer is done at an early stage so that the death rate of women may decrease to certain level. In this article, the detection and identification of ovarian cancer is done through selection of the images. The proposed research helps in detection of disease through different stages by acquiring the images. The Optimization algorithm employs for the selection and extraction of the features by using different operators which are employee, onlooker and scout bee with the MRI images. The classification and detection of the ovarian cancer is done using multi-layer convolutional neural network. The classification process is done using the selection and extraction of the features. The proposed work mainly emphasis on the evaluating and comparing the performance metrics, so that the performance of the image quality can be improved. The performance parameters are peak signal to noise ratio. The images are selected by extracting features to increase the accuracy rate, reduce the error rate and the time of the processing rate.

Future work, the identification of the particular cause and the REGION of the ovarian cancer can be done. The approach is the filtration of the images and detection of specific image through extracted features. The reduction in the probability of error rate and less time consumption for training and testing process using Fuzzy Logic in machine learning.

\section{REFERENCES}

1. Vine, M. F., Calingaert, B., Berchuck, A., \&Schildkraut, J. M ,"Characterization of prediagnostic symptoms among primary epithelial ovarian cancer cases and controls", Gynecologic oncology, 90(1), 2003, 75-82.

2. Nawgaje, D. D., \& Kanphade, R. D. ,"Hardware Implementation of Genetic Algorithm for Ovarian Cancer Image Segmentation", Proceedings of the International Journal of Soft Computing and Engineering (IJSCE), 2(6), 2012, 304-306

3. Smith, L. H., Morris, C. R., Yasmeen, S., Parikh-Patel, A., Cress, R. D., \& Romano, P. S. ,'Ovarian cancer: can we make the clinical diagnosis earlier?. Cancer",, 104(7), 2005, 1398-1407.

4. Goff, B. A., Mandel, L. S., Melancon, C. H., \&Muntz, H. G. ,"Frequency of symptoms of ovarian cancer in women presenting to primary care clinics", Jama, 291(22), 2004, 2705-2712.

5. Cokkinides, V., Albano, J., Samuels, A., Ward, M. E., \&Thum, J. M ,American cancer society: Cancer facts and figures", Atlanta: American Cancer Society, 22(1),2005, pp. 123-189.

6. Jemal, A., Tiwari, R. C., Murray, T., Ghafoor, A., Samuels, A., Ward, E., ..\&Thun, M. J. ,"Cancer statistics, 2004. CA: a cancer journal for clinicians," 54(1), 2004 8-29.

7. Biesecker, B. B., Boehnke, M., Calzone, K., Markel, D. S., Garber, J. E., Collins, F. S., \& Weber, B. L. ,'Genetic counseling for families with inherited susceptibility to breast and ovarian cancer". Jama, 269(15),1993,1970-1974.

8. Richards, C. S., Ward, P. A., Roa, B. B., Friedman, L. C., Boyd, A. A., Kuenzli, G., ... \&Plon, S. E. . Screening for 185 delAG in the Ashkenazim. American journal of human genetics, 60(5), 1997, 1085.

9. Bernhardt, B. A., Geller, G., Strauss, M., Helzlsouer, K. J., Stefanek, M., Wilcox, P. M., \&Holtzman, N.

A.," Toward a model informed consent process for BRCA1 testing: a qualitative assessment of women's attitudes", Journal of

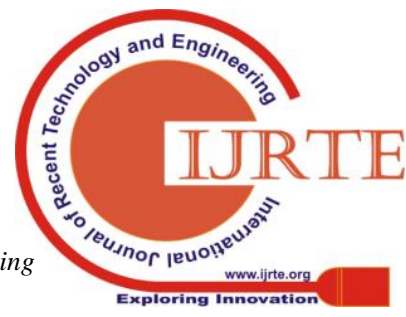


10. Lerman, C., Narod, S., Schulman, K., Hughes, C., Gomez-Caminero, A., Bonney, G., ...\&Fulmore, C.," BRCA1 testing in families with hereditary breast-ovarian cancer: a prospective study of patient decision making and outcomes",. Jama, 275(24), 1996, 1885-1892.

11. Struewing, J. P., Abeliovich, D., Peretz, T., Avishai, N., Kaback, M. M., Collins, F. S., \& Brody, L. C.," The carrier frequency of the BRCA1 185 delAG mutation is approximately 1 percent in Ashkenazi Jewish individuals", Nature genetics, 11(2), 1995, 198.

12. Lerman, C., Daly, M., Masny, A., \&Balshem, A, "Attitudes about genetic testing for breast-ovarian cancer susceptibility. Journal of clinical oncology", 12(4), 1994, 843-850.

13. Croyle, R. T., Smith, K. R., Botkin, J. R., Baty, B., \& Nash, J. ,Psychological responses to BRCA1 mutation testing: preliminary findings",. Health psychology, 16(1), 1997, 63

14. Lerman, C., Kerner, J., Gomez-Caminero, A., Hughes, C., Reed, M. M., Biesecker, B., \&Benkendorf, J. L. ,"Controlled trial of pretest education approaches to enhance informed decision-making for BRCA1 gene testing", Journal of the National Cancer Institute, 89(2), 1997 148-157.

15. Colditz, G. A., Sellers, T. A., \&Trapido, E.. "Epidemiology_-identifying the causes and preventability of cancer?",. Nature Reviews Cancer, 6(1), 200675.

16. Durfy, S. J., Bowen, D. J., McTiernan, A., Sporleder, J., \& Burke, W. ," Attitudes and interest in genetic testing for breast and ovarian cancer susceptibility in diverse groups of women in western Washington. Cancer Epidemiology and Prevention Biomarkers”,, 8(suppl 1), 1999, 369-375.

17.Vasavi, G., \&Jyothi, S. ," Classification and detection of ovarian cysts in ultrasound images",In 2017 International Conference on Trends in Electronics and Informatics (ICEI), 2017, (pp. 783-787).IEEE.

18. Yang, J., Kasberg, W. C., Celo, A., Liang, Z., Quispe, K., \& Stack, M. S. ,Post-translational modification of the membrane type 1 matrix metalloproteinase (MT1-MMP) cytoplasmic tail impacts ovarian cancer multicellular aggregate dynamics", Journal of Biological Chemistry, 292(32), 201713111-13121.

19. Schorge, J. O., Modesitt, S. C., Coleman, R. L., Cohn, D. E., Kauff, N. D., Duska, L. R., \& Herzog, T. J. ," SGO White Paper on ovarian cancer: etiology, screening and surveillance",Gynecologic oncology, 119(1), 2010,7-17.

20. Elkhadir, Z., Chougdali, K., \&Benattou, M. ,'Intrusion detection system using pca and kernel pca methods",In Proceedings of the Mediterranean Conference on Information \& Communication Technologies 2015, (pp. 489-497).Springer, Cham.

21. Bansal, J. C., Sharma, H., \&Jadon, S. S, "Artificial bee colony algorithm: a survey", International Journal of Advanced Intelligence Paradigms, 5(1-2),2013, 123-159.

\section{AUTHORS PROFILE}

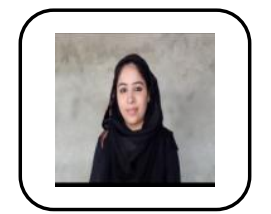

Ms.Uroosa Shafi is a student of Master's in Computer Science and Engineering at Chandigarh University, Gharuan, Mohali. She has done her Bachelor's in Computer Science from Baba Ghulam Shah Badshah University Rajouri. Her area of interest are Image processing \&Machine Learning.

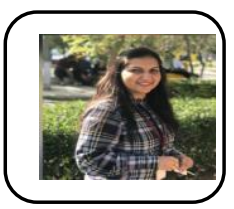

Prof.Sugandha Sharma is an Assistant Professor in Computer Science Department at Chandigarh University, Gharuan, Mohali.She has done B.Tech from Indo Global College Of Engineering and Master's Of Engineering from UIET,PU Chandigarh. 